\title{
FUZZY TENSION CONTROL OF THE WIRE ROD ROUGHING MILL
}

\author{
Tomáš BOROVSKÝ \\ Department of Electrical Engineering and Mechatronics, Faculty of Electrical Engineering and Informatics, \\ Technical University of Košice, Letná 9, 04200 Košice, Slovak Republic, \\ E-mail: tomas.borovsky@student.tuke.sk
}

\begin{abstract}
Tension control plays an important role in assuring product quality and process stability in steel rolling industry. Especially on looper control, there are a lot of applications where latest control theories had been applied, however, looperless interstand tension control of roughing mill remains a challenging problem. This paper proposes a looperless fuzzy interstand tension control system for a roughing mill of wire rod mill in Slovakia Steel Mills, a.s. Strážske. Review of looperless tension control techniques and the brief description of rolling process are also presented. Roughing mill simulation model with proposed control system was used to perform rolling simulation and results were compared with experimental results from the roughing mill with conventional control structure. The result from the test demonstrated reliability of the proposal.
\end{abstract}

Keywords: wire rod rolling, tension control, rolling torque, fuzzy control

\section{INTRODUCTION}

Interstand tension control is an important part of the process control in modern continuous wire rod mills. The interstand tension is a force, resulting from the increase in relative rolling velocity in successive stand and it affects mechanical properties of the product and mill performances [1]. Wire rod mill usually consists of roughing mill, intermediate mill and finishing mill. To maintain stable tension conditions, the looper control is usually used and many looper control technologies have been recently developed for intermediate and finishing mills. However, loopers cannot be applied to roughing mill due to the big workpiece cross sectional area. Hence, looperless techniques are used to control the interstand tension. In general, rolling with low tension in roughing mill is a fundamental condition to ensure the stable rolling quality [2], [3]. This paper proposes the fuzzy control structure for the roughing mill in Slovakia Steel Mills, a.s. Strážske.

The given roughing mill consists of six rolling stands $(S T D)$, individually driven by motors. Motor speed is controlled by $D C$ drives with closed loop speed control. The workpiece passes through the stands with box-oval and round-oval grooves in horizontal-vertical rolling sequence. A bar is rolled with calibre rolls and it is deformed 3 dimensionally. Therefore it is difficult to process a bar with high precision size. There is no rolling force measurement, no interstand tension measurement, no gauge sensor after the stand and no loop is formed between the stands. Hence, only motor torque and motor speed can be used as a process values for the tension control [3]. To maintain a stable process operation, the speed of the rolled workpiece leaving a previous stand is required to be identical to its entry speed into the adjacent downstream stand. If these two speeds differ, a longitudinal force, i.e. interstand tension will result between the adjacent stands [4]. This force has a crucial effect on a product quality and process stability [1], [3].

Tension torque can be caused by back or front tension. Back tension occurs, if relative rolling speed of given stand is higher than rolling speed of the upstream stand.
Front tension occurs if the relative rolling speed of given stand is lower than rolling speed of the downstream stand. Tension torque has impact on position of neutral point. With the variation of neutral point position along the roll bite length comes motor torque deviation due to the rolling force and tension torque deviation. Rolling force decreases with the increase of interstand tension while the tension torque increases with the increase of back tension and decreases with the increase of front tension [1]. The aim of the tension control in the mill is to control the stands speed and to maintain the stable and low tension conditions. In the finishing and intermediate mill, loop is usually formed intentionally between each two adjacent roll stands to buffer speed mismatches. The control task then turns to maintaining suitable loop height [1], [4]. If the free loop is present between two adjacent stands, tension force can be neglected. Loopers, however, cannot be installed to the roughing mill due to the size of the workpiece passing through there. The roll speed selection in roughing mill has been frequently based more on experience and wrong set up can be corrected by the manual adaptation of the speed reference according the torque deviations after the impact speed drop [5]. Current practice is usually to employ a human operator who manually controls the tension [4], or automatic Low Tension Control (LTC) or Minimum Tension Control (MTC) based on torque comparison method with PID control is implemented in the control system [6], [4]. The most advanced system is Interstand Dimension Control (IDC), which can control the workpiece dimensions between the stands. Gauge sensors are installed between the stands and closed control loop is used to continuous maintain the desired cross sectional area. Height of the workpiece is controlled by gap adjustment, whereas workpiece width is controlled by speed ratio, i.e. by interstand tension [7]. Given wire rod mill has conventional, sensor-less control system based on torque comparison method in roughing mill. As the torque comparison method with PID control does not meet today demands on product quality and IDC control requires additional costs, Fuzzy control is a good choice to tension control system design for given roughing mill [8], [10], 
[11], [12]. More robustness control and decrease of the time required to the tension elimination are expected from this proposal.

\section{ROLLING PROCESS AND TENSION CONTROL}

When the billet passes the first stand, motor torque is equal to the rolling torque. Once the billet enters consequent stand, interstand tension can occur as a result of relative rolling velocity variation of continuous rolling sequence and motor torque of both stands is affected by this tension force. First stand by forward tension, second stand by backward tension. Hence, motor torque of given stand before and after the loading of successive stand can be used as a tension indicator [3], [8]. In Fig. 1 is shown rolling sequence of first three stands. The droop in STD01 motor torque feedback fue to the front tension is shown in detail $A$. Another torque deviation due to the nonhomogeneous temperature along the billet is shown in detail $B$. Effect of back tension is not so clear as the effect of front tension, and it is shown in detail $C$.

When there is a torque droop after the workpiece enters consequent stand, speed ratio between the stands should be decreased by a speed correction to given stand (upstream correction). Exact estimation of the correction requires many input parameters and can change with the variation of rolling mill set up [3]. Operators usually apply an estimated correction based on their experiences, but this cannot lead to the stable and high quality production [8]. (1),

The total torque $T$ actuating the motor shaft is given by

$$
T=T_{0}+T_{r}+T_{p}+T_{f t}+T_{b t}+T_{d}
$$

where:

$T$-Total torque acts on motor shaft

$T_{0}-$ Friction torque

$T_{r}-$ Rolling torque (Torque from rolling force and rolls pins friction)

$T_{p}$ - Torque from pins friction during the rolling

$T_{f t}-$ Torque from forward tension

$T_{b t}$ - Torque from backward tension

$T_{d}$ - Dynamic torque

While $T_{d}$ and $T_{0}$ depend on rolling stand design, rolling $\left(T_{r}\right)$, pins friction $\left(T_{p}\right)$ and tension $\left(T_{f t}, T_{b t}\right)$ torque are complex and variable quantities, highly coupled, and they are functions of many rolling parameters and rolling and tension forces, which are affecting given stand [3], [8]. Rolling force $F_{r}$ and rolling torque $T_{r}$ are given by (2) and (3), respectively, where $\sigma_{y}$ is stress component in vertical direction, $b$ is a width of approximated workpiece-roll surface area and $L_{r}$ is roll-bite length. Torque from pins friction is given by (4), where $f_{p}$ is pins friction coefficient and $D_{p}$ is pins diameter. Forward $T_{f t}$, tension torque and backward tension torque $T_{b t}$ is given by (5) and (6), respectively, where $D_{\text {eff }}$ is rolls effective diameter, $A_{b}$ and $A_{f}$ is workpiece cross sectional area in front and back of
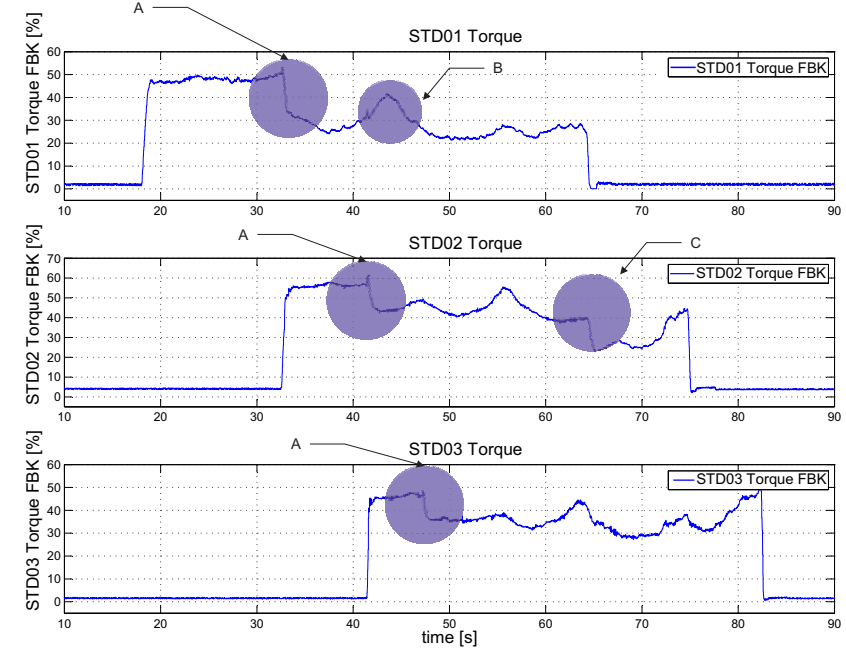

Fig. 1 Motor torque feedback of the first three stands during billet rolling. A-STD01 motor torque droop due to the front tension, B-STD01 motor torque increases due to the temperature deviation, C-STD02 motor torque droop due to the back tension.

the roll-bite length, $\sigma_{f}$ and $\sigma_{b}$ is front and back axial stress [13].

Since there is no rolling or tension force measurement in the mill, components of the torque which is affecting the motor shaft during the rolling sequence cannot be identified separately. Estimation of all these components requires knowledge of rolling parameters as the workpiece cross sectional area, effective roll diameter, friction coefficient and stress components. However, these parameters vary during the rolling process (due to the temperature deviation, roll wear, frictions factor deviation and inaccurate set up of the roll gap) they can be hardly used to calculate the rolling torque components [9], [4]. Hence, in given roughing mill only the torque comparison method can be used, where the motor torque is used as a tension indicator. This paper reports a fuzzy control system to realize a robust tension control based on torque comparison method.

On a continuous rolling mill, fixed speed ratio must be achieved to get stable mass flow. Interaction between upstream and downstream stand is not allowed except the tension control. The feed-forward, so-called Cascade Speed Control (CSC), is used to maintain the stable speed ratio between the stands [6]. With CSC, the roll speeds of all upstream stands are changed accordingly when the roll speed of downstream stand is being corrected by its tension controller so that the induced speed change of each upstream stand is proportional to that of its adjacent downstream stand [4]. Reference speed relation between the stands in rolling line is given by (7), where $v_{i}$ and $v_{i+1}$ are the speeds of $i$-th and ( $i+1)$-th stand respectively, $R_{i}$ is the reduction factor of $i$-th stand, $K_{i}$ is the correct factor for reduction of $i$-th stand. $K_{i}$ is evaluated by tension control of given stand [6]. Speed references are highly coupled and any change of speed in downstream stand must be reflected to proportional speed change in upstream stand [4]. 


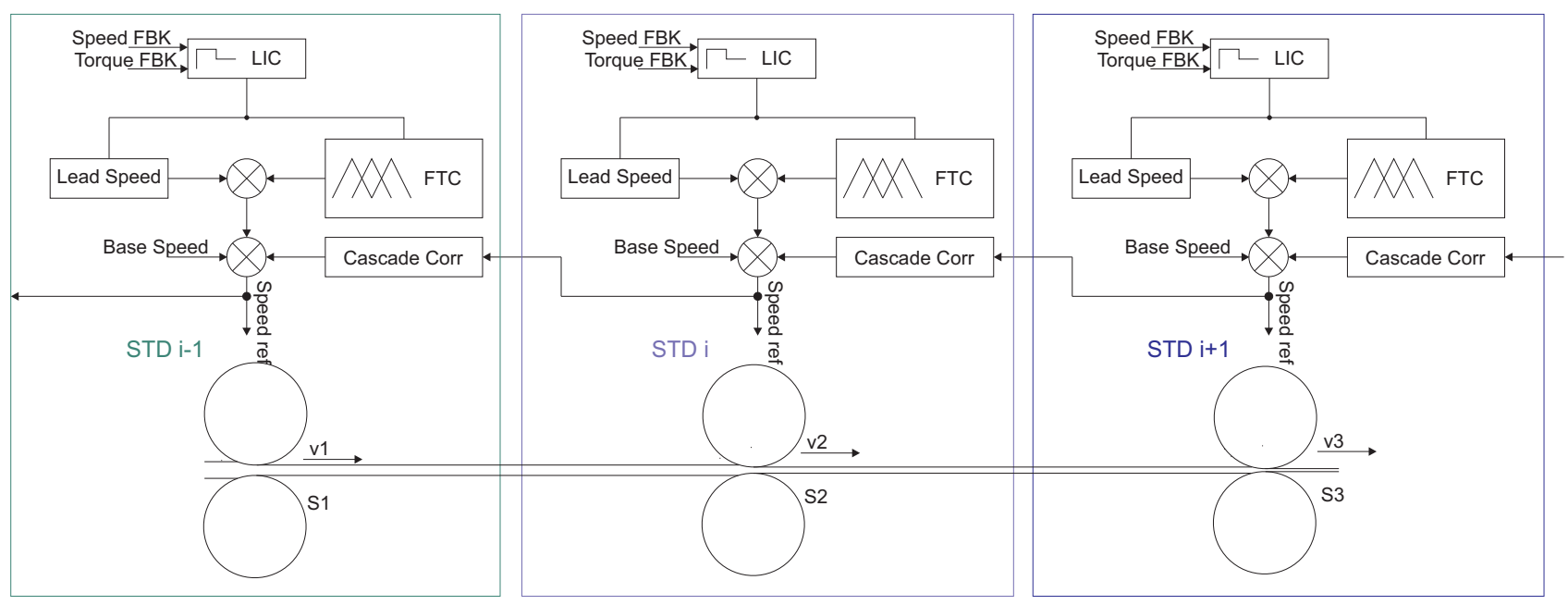

Fig. 2 Principled scheme of speed control chain with fuzzy tension controller

$$
\begin{aligned}
& F_{r}=2 \int_{0}^{L_{r}} b \sigma_{y} d x \\
& T_{r}=4 \int_{0}^{L_{r}} b \sigma_{y}\left(L_{r}-x\right) d x \\
& T_{p}=\frac{F_{r} f_{p} D_{p}}{2} \\
& T_{f t}=\frac{D_{e f f} A_{f} \sigma_{f}}{2} \\
& T_{b t}=\frac{D_{e f f} A_{b} \sigma_{b}}{2} \\
& v_{i}=\frac{v_{i+1}}{R_{i}}\left(1+K_{i}\right)
\end{aligned}
$$

\section{FUZZY TENSION CONTROLLER}

The proposed control structure consists of fuzzy tension controller (FTC), cascade speed controller (CSC) and additional logic with interval controller $(L I C)$. In Fig. 2 is shown principled scheme of proposed control structure for first three stands, with two interstand zones.

Cascade speed control maintains stable speed ratio of upstream stands when the speed of given stand is corrected by tension controller.

Additional logic (LIC) calculates the workpiece head position along the rolling mill and manages tension controller, lead speed, measurements and auxiliary calculations [3], [10]. Since the billet enters the given stand, average rolling torque $T_{a v g}$ is calculated as the average value of feedback torque for given stand in the defined rolling length. When the billet enters consequent stand, tension error (LTC error) is calculated as a difference between the reference and actual feedback torque. Reference torque is calculated as a sum of the average rolling torque $T_{\text {avg }}$ and torque set $T_{\text {set }}$. $T_{\text {set }}$ is used to keep desired minimum tension to prevent the loopering between the stands. FTC for each stand is active only during the defined rolling length and generates a speed correction only for the given stand. FTC of given stand must be stopped before workpiece enters consequent stand, because the tension which can come from consequent stand can influence also to the motor torque feedback of given stand. Therefore, only one FTC can be active in the roughing mill during the billet rolling sequence, and FTC are changing as the workpiece enters subsequent stand. When the rolling is finished, new speed references for all stands are stored and used for next billet. When the next billet comes, LIC activates given FTC, new torque reference is calculated and another tension control sequence is running. Speed of the given stand is adapted billet by billet to maintain demanded tension conditions. During the stable rolling process, rolling grooves progressively wear. It is mostly a small change, but the cross-sectional area variation results into the tension deviation that consequently leads to FTC action and speed ratio correction. FTC should be able to identify these small changes in tension torque and gradually correct the speed ratio. However, due to the non-homogenous temperature of the billet, small or big deviation in the rolling torque can occur, that consequently affects the tension torque calculations. Small deviation should not activate the FTC, while big deviation must be considered. Moreover, when the mill set-up changes dramatically, big tensions can occur and FTC response must be very rapid.

FTC emulates the human operator reasoning based on the torque comparison method to generate the motor speed correction. Input is the torque difference $e_{i}$ and the change

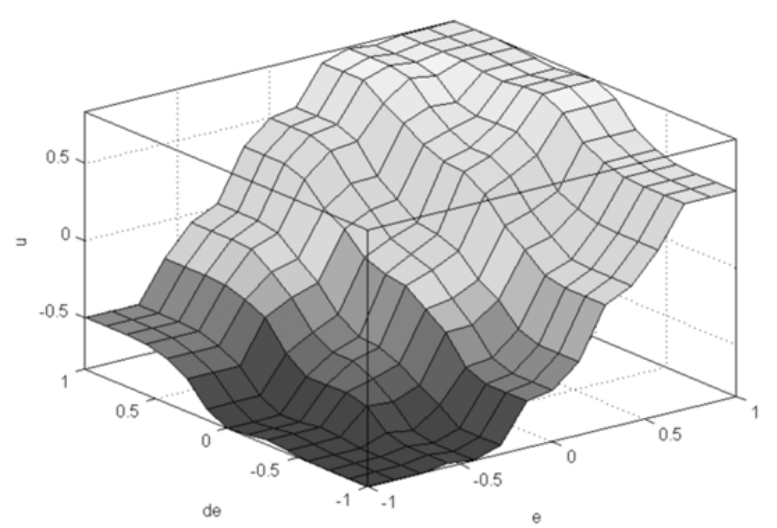

Fig. 3 FTC Surface 
in the torque difference $\Delta e_{i}$, output is the speed correction to given stand $\Delta v_{i}$. Membership functions selected for inputs and output are defined as follows:

- $e$ :

$\begin{array}{ll}\mathrm{o} & \mathrm{VN}\left[\begin{array}{llll}-1 & -1 & -0.7 & -0.4\end{array}\right] \\ \mathrm{o} & \mathrm{N}\left[\begin{array}{lll}-0.7 & -0.4 & -0.1\end{array}\right] \\ \mathrm{O} & \mathrm{Z}\left[\begin{array}{llll}-0.3 & 0 & 0.3\end{array}\right] \\ \mathrm{O} & \mathrm{P}\left[\begin{array}{llll}0.1 & 0.4 & 0.7\end{array}\right] \\ \mathrm{o} & \mathrm{VP}\left[\begin{array}{lllll}0.4 & 0.7 & 1 & 1\end{array}\right]\end{array}$

- $\Delta e$ :
O $\mathrm{N}[-1-1-0.6-0.1]$
o $\mathrm{Z}\left[\begin{array}{llll}-0.6 & 0 & 0.6\end{array}\right]$
o $\quad \mathrm{P}\left[\begin{array}{lllll}0.1 & 0.6 & 1 & 1\end{array}\right]$

- $\Delta v$ :
o $\mathrm{VN}[-1-1-0.9-0.5]$
o $\mathrm{N}[-0.9-0.5-0.1]$
O Z $\left[\begin{array}{lll}-0.5 & 0 & 0.5\end{array}\right]$
$0 \quad \mathrm{P}\left[\begin{array}{lll}0.1 & 0.5 & 0.9\end{array}\right]$
o VP $\left[\begin{array}{llll}0.5 & 0.9 & 1 & 1\end{array}\right]$

In Fig. 3 is shown control surface of FTC; rules based on human operator experiences are shown in Table 1.

Table 1 Rule Base

\begin{tabular}{cccccc}
\hline & $\mathrm{VN}$ & $\mathrm{N}$ & $\mathrm{Z}$ & $\mathrm{P}$ & $\mathrm{VP}$ \\
\hline $\mathrm{N}$ & $\mathrm{VN}$ & $\mathrm{VN}$ & $\mathrm{N}$ & $\mathrm{Z}$ & $\mathrm{P}$ \\
$\mathrm{Z}$ & $\mathrm{VN}$ & $\mathrm{N}$ & $\mathrm{Z}$ & $\mathrm{P}$ & $\mathrm{VP}$ \\
$\mathrm{P}$ & $\mathrm{N}$ & $\mathrm{Z}$ & $\mathrm{P}$ & $\mathrm{VP}$ & $\mathrm{VP}$
\end{tabular}

$\Delta v$ - output, $e$ - error, $\Delta e$ - change of error

\section{ROLLING SIMULATION AND ROLLING TEST}

Rolling mill set up and rolling parameters comes out from rolling sequence for specific product: rebar $\phi 12 \mathrm{~mm}$.
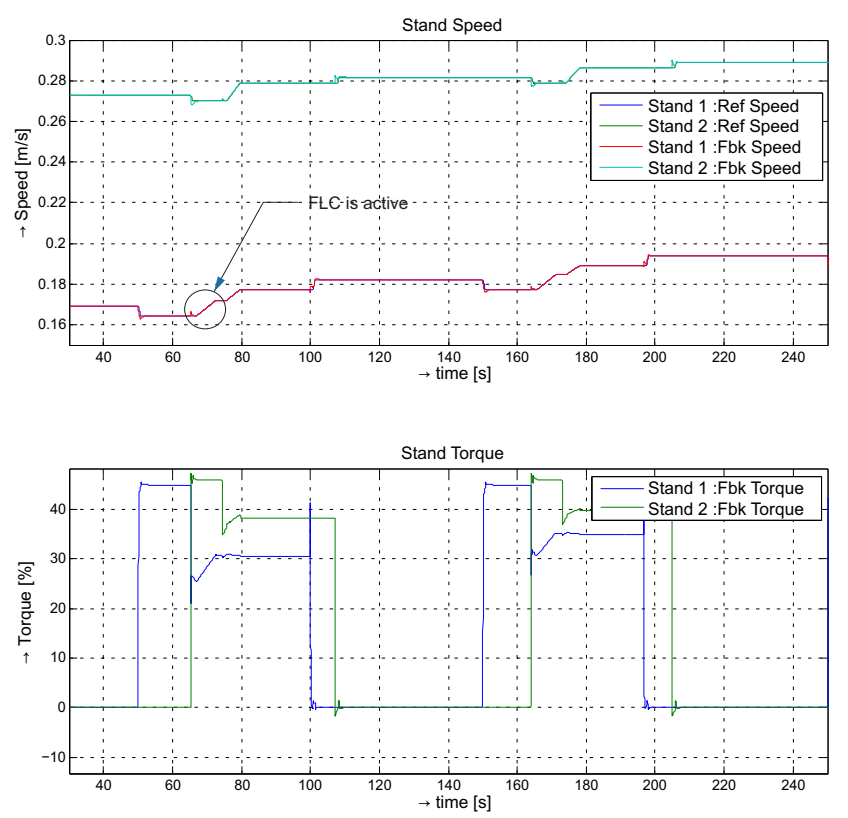

Fig. 4 Detail of the FTC controller action during the rolling simulation. After first billet, speed of the STD01 was increased by tension controller by approximately $8 \%$ and $L T C$ error was decreased by approximately $25 \%$.
Simulaton model is created in Matlab Simulink and it includes first three stands of roughing mill, two interstand zones with two workpiece models and additional control logic. Speed of first two stands is controlled by fuzzy tension controller to maintain suitable tension conditions between these stands. Tension between STD01-STD02 is controlled by speed of stand STD01, while tension between STD02-STD03 is controlled by speed of stand STD02.

Dynamic model of workpiece which is used for this simulation consist of static and dynamic part. Static part represents rolling torque in steady state conditions and it was obtained experimentally. Dynamic part represents deviation of rolling torque due to the tension between the stands, and it is related to the speed of two successive stands. The relation was identified experimentally, as a linear function of the speed of these stands [3].

Control structure consists of FTC for STD01 and STD02 and additional logic LIC. LIC includes CSC, Impact droop function (Lead speed), interval control and other auxiliary services, which are important to maintain fully automatic rolling process. All parameters and functions are based on real rolling mill parameters [3].

Initial speed set was selected, to simulate the similar tension conditions as they were during the real rolling test. Speed ratio and LTC error during continuous rolling simulation can be seen in Fig. 7. Speed and torque feedback of first two stands during simulation can be seen in Fig. 4 and Fig. 6. Speed reference droop, which occurs when billet enters the $S T D$, is due to the impact droop function, which is described in [3]. After the billet enters consequent stand, FLC is increasing the speed of STD01 during defined time interval and the final speed reference is stored for next billet. After few billets are rolled, the tension is marginal as it can be seen in Fig. 6 and Fig. 7. Speed ratio and LTC error during continuous rolling test
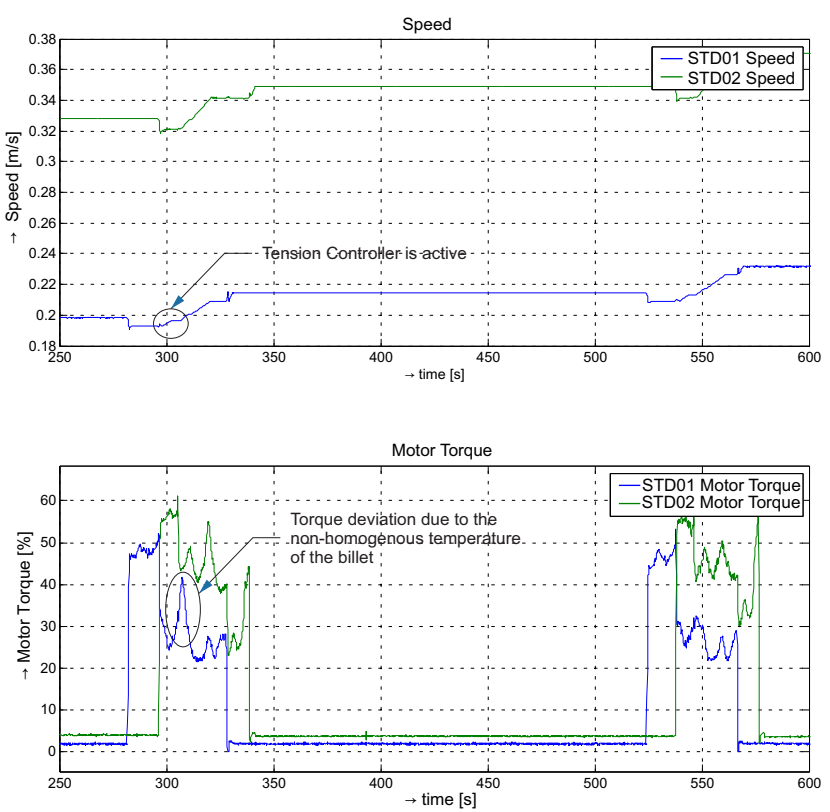

Fig. 5 Detail of the tension controller action during the real rolling test. After first billet, speed of the STD01 was increased by tension controller by approximately $1.75 \%$ and LTC error was decreased by approximately $7 \%$. 

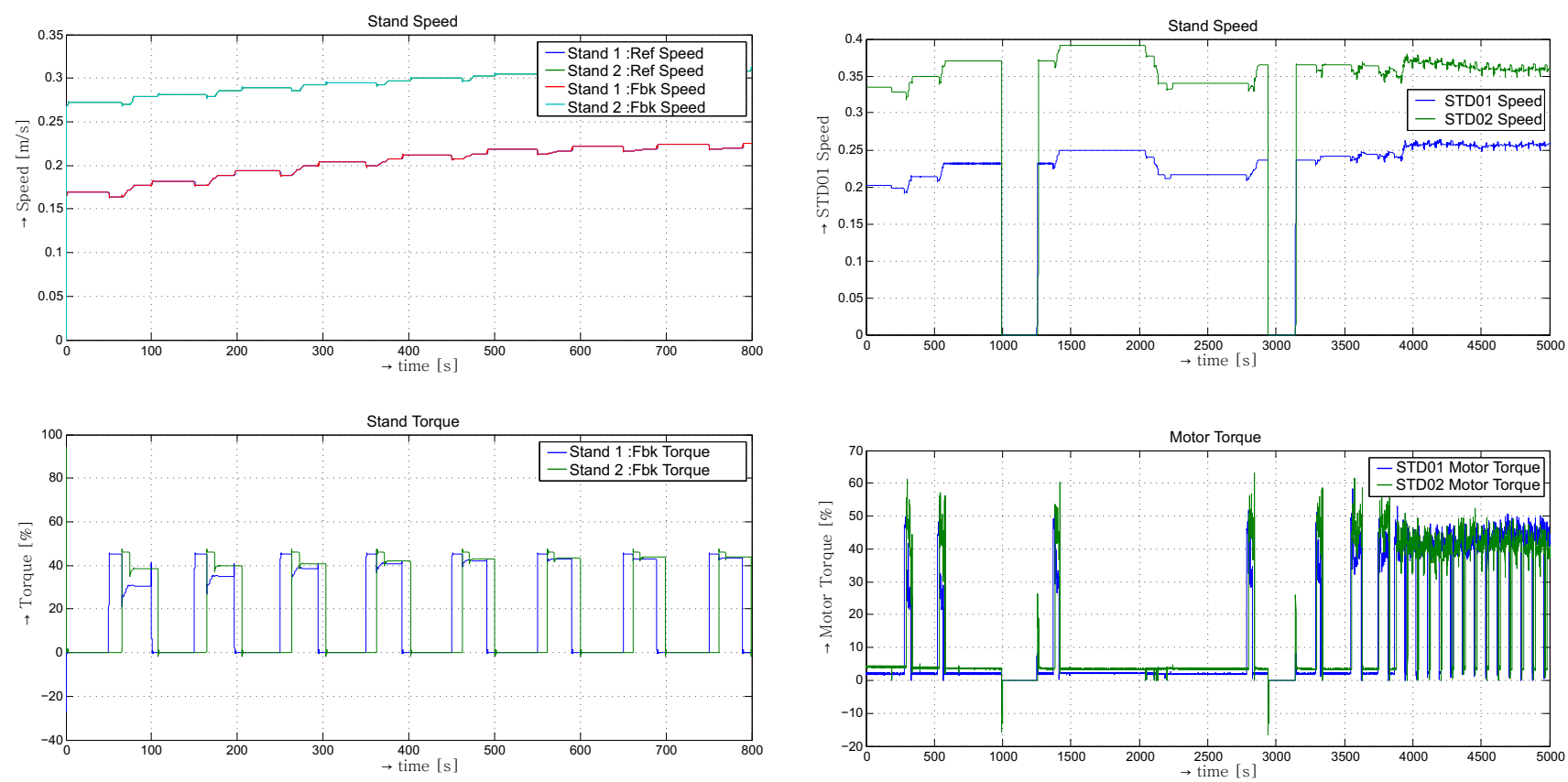

Fig. 6 FTC controller actions during the rolling simulation. The torque droop is decreased rapidly after first 2-3 billets.

Fig. 8 Tension controller actions during the real rolling test. The torque droop is decreased slowly, after 6 billets the rolling mill starts to roll continuously.
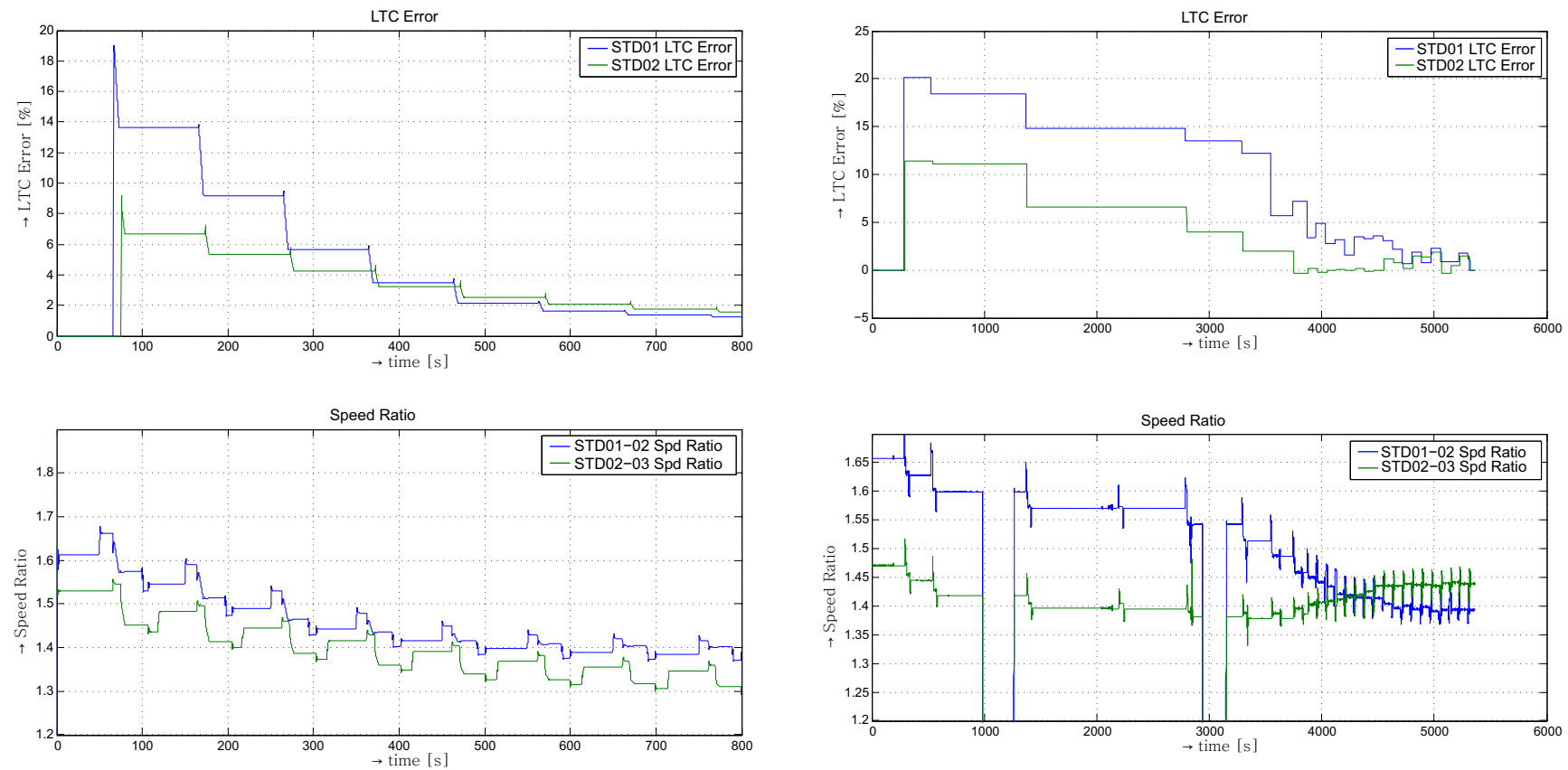

Fig. 7 LTC error and speed ratio changes during the continuous rolling simulation. LTC error changes only when the FTC is active. After tension controller action, new reference speed for STD01 and consequently new speed ratio between STD01-

STD01 is achieved for next billet. FTC needs approximately 4 billets to decrease LTC error lower than $5 \%$ and the speed ratio between STD01-STD02 is finally stabilized on level around 1.4.

Fig. 9 LTC error and speed ratio changes during the continuous rolling test. LTC error starts with approximately $20 \%$. After first two billets there is a stoppage in the mill due to the gap set-up change. Another stoppage is after next two billet. Tension controller needs roughly 8 billets to decrease $L T C$ error lower than $5 \%$ and the speed ratio between STD01-STD02 is finally stabilized on level around 1.4. 
can be seen in Fig. 9. Speed and torque feedback of first two stands during the rolling test can be seen in Fig. 5 and Fig. 8. Speed droop, which occurs when billet enters the $S T D$, is due to the impact droop function [3]. After the billet enters consequent stand, LTC tension controller is increasing the speed of STD01 during defined time interval and the final speed reference is stored for next billet. In the beginning of rolling test, the tension torque was approximately $20 \%$. After two billets is a stoppage in the mill due to the gap set-up and after there is another mill stoppage. It takes to roll approximately 8 billets to decrease the tension under the $5 \%$ level of the tension torque. In Fig. 4 and Fig. 5 is shown the detail of tension controller action during the simulation and rolling test for two rolling sequences. The speed of the STD01 is changed by $8 \%$ and tension is decreased by $25 \%$ during the simulation, whereas the speed of the STD01 changes by $1.75 \%$ and tension is decreased by $7 \%$ during the rolling test, after one rolling sequence. FTC has bigger gain if the error is too big and thus the output is bigger and effect is faster. When the tension is decreased, decreases also the response of the FTC as it can be seen in Fig. 6 and Fig. 7. Some differences in speed ratios and STD speeds, between the simulation and the rolling test are caused by roll gap set-up changes during the rolling test.

An inaccuracy of the tension torque during the rolling test can be also caused due to the temperature deviations along the billets, as it can be seen in Fig. 5. The temperature deviations are caused by nonhomogeneous billet heating conditions in Furnace, and they cannot be avoided. Thus, proposed control system should have additional control logic to take into consideration the influence of the variance of temperature of bar called "Skid-Mark" [11]. When the Skid-Mark is big, the the calculation of the error for tension controller could be affected and consequently the output of the controller is also incorrect.

\section{CONCLUSION}

This paper describes a tension control principles and techniques in wire rod mill and proposes the fuzzy tension control for roughing mill in Wire Rod Mill Slovakia Steel Mills, a.s. Strážske. Rolling simulation with FLC was compared to real rolling test with conventional LTC tension control. Result demonstrates that the proposed control chain is capable for this application and it can bring faster and more robust tension control. Moreover, the proposal does not account with the installation of any additional facilities.

Next work will deal with the negative influence of the temperature deviations along the billet length (SkidMark), which can cause an incorrect action of tension controller.

\section{REFERENCES}

[1] YOUNGSEOG, L.: Rod and Bar Rolling: Theory and Applications, CRC Press, Korea, 2004.

[2] ERIKSSON, C.: Roll Pass Design for Improved Flexibility and Quality in Wire Rod Rolling, Doctoral Dissertation, Royal Institute of Technology, Stockholm, Sweden, 2004, ISBN 91-628-6232-4.
[3] BOROVSKÝ, T.: Simulation and Analysis of Wire Rod Rolling, SCYR 2015 - Proceedings of the 15th Scientific Conference of Young Researchers, Herl'any, Slovak Republic, 2014, pp. 114-115, ISBN 978-80-553-2130-1.

[4] LI, G. - JANABI-SHARIFI, F. - WITNISKY, L.: Decoupling of Multiple Stand Interactions in Looperless Rolling Control Process, ICIT'02 - IEEE International Conference on Industrial Technology, Bangkok, Thailand, pp. 821-826, doi: 10.1109/ ICIT.2002.1189273.

[5] KORHONEN, A. S. - NIKKILA, K. J.: A Study on the Rod Exit Speed in Wire Rod Rolling, Scandinavian Journal of Metallurgy 3, pp. 241-244, 1974.

[6] SUN, X. - SUN, H. F.: Speed cascade control system for bar and wire rod mills, ABB Value Paper, ABB China Ltd, 2009.

[7] SOLLANDER, D. N.: Upgrading rod and bar mills with state-of-the-art control technology, $A B B$ Automation Systems AB, Sweden, 1999.

[8] JANABI-SHARIFI, F. - GUOMINI, L.: Fuzzy Tension Control Scheme for Roughing and Intermediate Rolling Mills, ANNIE - Artificial Neural Networks in Engineering Conference, St. Louis, USA, 2002.

[9] LIU, J.: Design and Analysis of Intelligent Fuzzy Tension Controllers for Rolling Mills, Master Thesis, University of Waterloo, Waterloo, Canada, 2002.

[10] LI, G. - JANABI-SHARIFI, F.: Fuzzy Multiple Stand Tension Control of a Roughing Mill, Fuzzy Information Processing Society, NAFIPS (560-565), Annual Meeting of the North American 2002, ISBN 0-7803-7461-4.

[11 OGAI, H. - FUJJI, A. - BABA, K. - NOGUCHI, Y.: Free Tension Set-up of Rod Bar Rolling by Fuzzy Inference Method, IEEE Industrial Electronics, Control and Instrumentation, IECON '91, 1991.

[12] LI, G. - JANABI-SHARIFI, F.: Fuzzy looperless tension control for hot strip rolling, Journal Fuzzy Sets and Systems, Volume 160 Issue 4, 2009, pp. 521-536, doi:10.1016/j.fss.2008.04.013.

[13] BAYOUMI, L. S. - LEE, Y.: Effect of Interstand Tension on Roll Load, Torque and Workpiece Deformation in the Rod Rolling Process, Journal of Materials Processing Technology, Vol. 145, pp. 713, 2004, doi:10.1016/S0924-0136(03)00581-8.

Received September 7, 2016, accepted December 9, 2016

\section{BIOGRAPHY}

Tomáš Borovský (Ing.) was born on $28^{\text {th }}$ May 1987 in Trebišov, Slovakia. In 2011 he graduated at the Technical University of Košice and received the engineering degree. He is currently a PhD. student at Department of Electrical Engineering and Mechatronics, TU Košice, Slovakia. From 2011 to 2015 he was also working as automation engineer in wire rod mill in Strážske. His field of research interests are the control of electrical drives and control of rolling process. 